Journal of Engineering and Applied Sciences 14 (18): 6890-6896, 2019

ISSN: 1816-949X

(C) Medwell Journals, 2019

\title{
Design and Experimental Study of Two-Stage Hydrocyclones for Oil-Water Separation
}

\author{
Maryam Ibrahim Chasib and Raghad Fareed Qasim \\ Department of Chemical Engineering, University of Baghdad, Baghdad, Iraq
}

\begin{abstract}
Separation of oil in water emulsion is very challenging issue, especially, in industrial applications. Two identical hydrocyclones are designed and used to separate oil (kerosene) from oil in water emulsion. The operational variables such as split ratio $(0.1-0.9)$, feed flow rate $(6-12 \mathrm{~L} / \mathrm{min})$ and inlet oil concentration $(250-1250 \mathrm{ppm})$ as well as the design parameters such as vortex finder length $(0.6-2.7 \mathrm{~cm})$ are investigated for single and double hydrocyclones. It was shown that the separation efficiency is enhanced by connecting two hydrocyclones in series. The optimum conditions were estimated using Minitab program with $2^{3}$ factorial design of experiments. It was shown that optimum feed flow rate $Q_{i}=12 \mathrm{~L} / \mathrm{min}$, inlet oil concentration $C_{i}=250 \mathrm{ppm}$, split ratio $\mathrm{F}=0.9$ and $\mathrm{VFL}=1.3 \mathrm{~cm}$ gave maximum obtainable separation Efficiency $(\mathrm{Ej}=94.78 \%)$ and minimum Pressure Drop Ratio (PDR $=0.895$ ) for single hydrocyclone. This efficiency increased to $95.2 \%$ and PDR decreased to 0.86 by using two hydrocyclones.
\end{abstract}

Key words: De-oiling hydrocyclone, double-stage hydrocyclone, design, experimental study, oil-water separation, water emulsion

\section{INTRODUCTION}

Hydrocyclone is a simple device entered to the industry in 18th century. Initially, it is designed for separating solid-liquid then it applied for liquid liquid separation (Kharoua et al., 2010b). De-oiling hydrocyclones were used for multiphase separation in various industries such as removing emulsified oil from oily water or oil spill (Motin and Benard, 2017). Therefore, it is used for separating different materials from liquids because of its compactness low cost, having no moving parts no requiring for any chemical additives and simple operation (Saidi et al., 2012). Separation of oil in water emulsion by hydrocyclone is based on the centrifugal force that generated by injection the pressurized feed tangentially in the hydrocyclone body according to the density difference between oil and water. There are two vortices created in its body. One of them is called forced vortex that carries oil close to the hydrocyclone axis and directs to overflow stream while water is carried in the free like vortex close to hydrocyclone wall and directs to underflow stream as shown in Fig. 1 (Gomez et al., 2002).

Many researchers investigated hydrocyclones design and operation using simulation by CFD or by doing experiments, Young et al. (1994) confirmed that $C_{i}$ is not influenced the separation efficiency of oil-water hydrocyclone while Gomez et al. (2002) concluded that at feed oil concentration higher than $10 \%$ high separation efficiency was achieved of oil-water hydrocyclone. Kharoua et al. (2010a) studied the effect

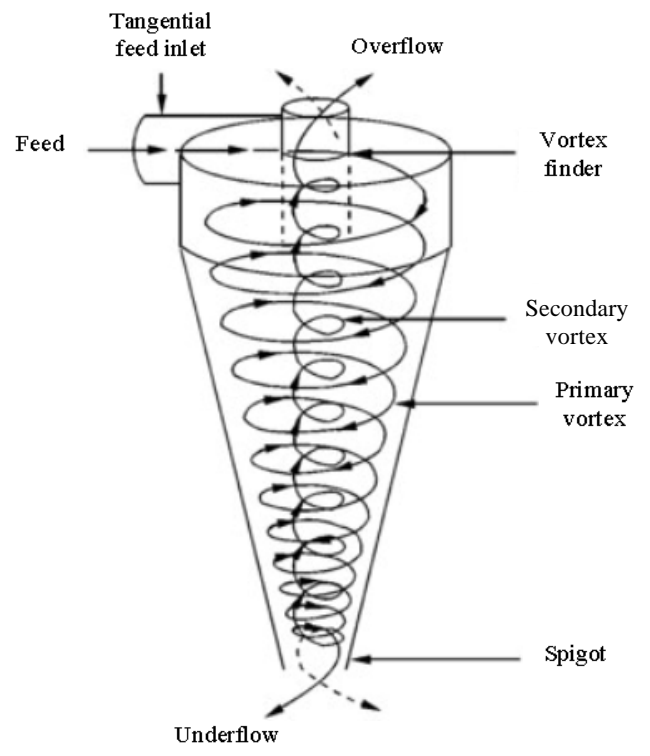

Fig. 1: Flow features of the hydrocyclone (Cilliers, 2000)

of operational variables on the separation of de-oiling hydrocyclone by using CFD Software. They concluded that flow rate and droplet size affected the efficiency while feed oil concentration had insignificant effect on it.

Hosseini et al. (2015) also confirmed that increasing flow rate and oil droplet diameter reduplicated the efficiency at the studied range. $\mathrm{C}_{\mathrm{i}}$ did not affect $\mathrm{Ej}$ by using CFD for de-oiling hydrocyclone. Yan et al. (2015) made experiments to separate oil of density $860 \mathrm{~kg} / \mathrm{m}^{3}$ from

Corresponding Author: Maryam Ibrahim Chasib, Department of Chemical Engineering, University of Baghdad, Baghdad, Iraq 


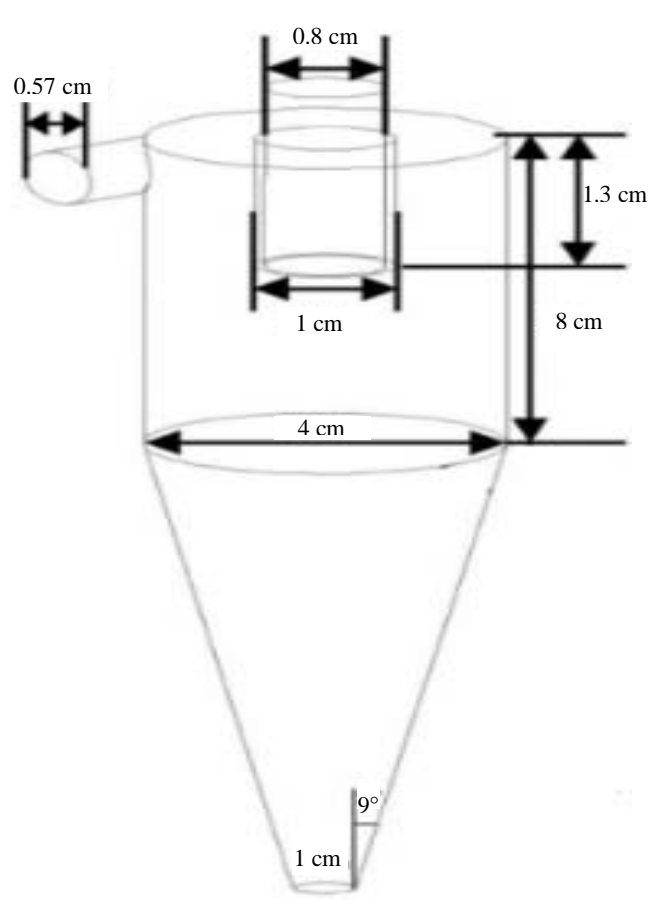

Fig. 2: The dimensions of designed hydrocyclone

\begin{tabular}{|c|c|c|}
\hline Dimension & Equation & Values (units) \\
\hline$d_{c}$ & $\mathrm{~d}_{50}=4.1^{*}\left(\left(\mathrm{dc}^{3}\right)^{* / \mathrm{Q}^{*}}(\rho-\sigma)\right) .5$ & $4(\mathrm{~cm})$ \\
\hline$d_{i}$ & $\mathrm{~d}_{\mathrm{i}}=\mathrm{d}_{\mathrm{c}} / 7$ & $0.57(\mathrm{~cm})$ \\
\hline$d_{o}$ & $\mathrm{~d}_{\mathrm{o}}=\mathrm{d}_{\mathrm{d}} / 5$ & $0.8(\mathrm{~cm})$ \\
\hline$d_{u}$ & ---------- & $1(\mathrm{~cm})$ \\
\hline $\mathrm{L}_{1}$ & $\mathrm{~L}_{1}=2^{*} \mathrm{~d}_{\mathrm{c}}$ & $8(\mathrm{~cm})$ \\
\hline VFL & $V F L=d_{c} / 3$ & $1.3(\mathrm{~cm})$ \\
\hline$\theta$ & ----------- & $9^{\circ}$ \\
\hline$\underline{\mathrm{h}}$ & 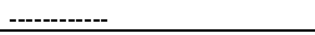 & $1(\mathrm{~cm})$ \\
\hline
\end{tabular}

Table 2: Kerosene properties at $\left(40^{\circ} \mathrm{C}\right)$ and ambient pressure

\begin{tabular}{ll}
\hline Properties & Values \\
\hline Viscosity $(\mathrm{cp})$ & 1.583 \\
Density $\left(\mathrm{g} / \mathrm{cm}^{3}\right)$ & 0.78 \\
\hline
\end{tabular}

water in hydrocyclone and concluded that the separation efficiency significantly influenced by split ratio and flow rate while $\Delta$ pressure drop changed with rotating speed and flow rate. Fan (2016) investigated that at $0.5 \%$ feed oil concentration and $10 \%$ distribution ratio, de-oiling hydrocyclone separates $80 \%$ of $15 \mu \mathrm{m}$ oil droplet size and $50 \%$ of $9.2 \mu \mathrm{m}$ oil droplet size.

De-oiling hydrocyclone design: Two de-oiling hydrocyclones were designed according to Bradley design Bradley (1965), Barbosa et al. (2003). The design equations were applied after measuring oil droplet size, oil density and oil viscosity Table 2 . The equations used to obtain dimensions of designed hydrocyclone are listed in Table 1 and illustrated in Fig. 2. The average oil droplet size was $\left(\mathrm{d}_{50}\right) 20 \mu \mathrm{m}$ as measured by optical microscope (50-2000 X, China).

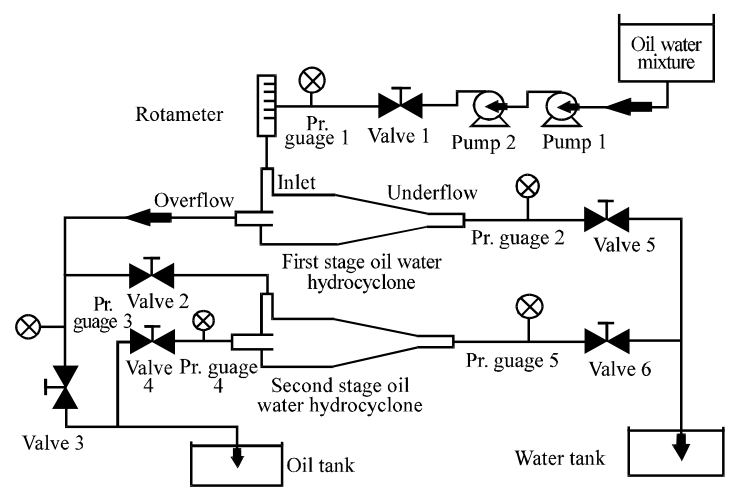

Fig. 3: Schematic diagram of the experimental setup

\section{MATERIALS AND METHODS}

The oil used in the experiments was kerosene (purchased from local market) and its measured density and viscosity are listed in Table 2 . The experiments were carried out by filling feed tank with simulated oily wastewater at the desirable inlet oil concentration and turning on the 2 pumps $(0.5 \mathrm{hp}$, China; $1 \mathrm{hp}$, Italy) in the experimental set up as shown in Fig. 3. Opening valves (1,3 and 5) and closing valves (2, 4 and 6$)$ for achieving 1 hydrocyclone's experiments while valves $(1,2,4,5$ and 6$)$ were opened and valve (3) was closed for two hydrocyclone's experiments. For the 2 cases valves of outlet streams were adjusted to obtain the desirable split ratio $(\mathrm{F})$ (where $\mathrm{F}=\mathrm{Q}_{\mathrm{J}} / \mathrm{Q}_{\mathrm{i}}$ ). The influence of changing flow rate $(6,8,10,12 \mathrm{~L} / \mathrm{min})$ split ratio $(0.1,0.3,0.5,0.7,0.9)$ and feed oil concentration $(250,500,750,1000,1250 \mathrm{ppm})$ was studied on the separation efficiency for 1 and 2 cyclones. Oil in water concentrations for outlet streams for each experiment were measured using UV spectrophotometry ((0-3) absorbance, USA) and pressures for all streams were recorded. The experimental data were used with the aid of Minitab program to determine the optimum set of operational conditions for each case namely, one and two hydrocyclones. The optimum conditions were applied with variable vortex finder length $(0.6,1.3,2$ and $2.7 \mathrm{~cm})$.

\section{RESULTS AND DISCUSSION}

Results contain the influence of operational variables (feed oil concentration, feed flow rate and split ratio) and the design parameter Vortex Finder Length (VFL) on the separation efficiency and pressure drop ratio. Also, optimization of these variables of 1 and 2 hydrocyclones was performed.

Separation Efficiency (Ej): Separation efficiency is defined by: 

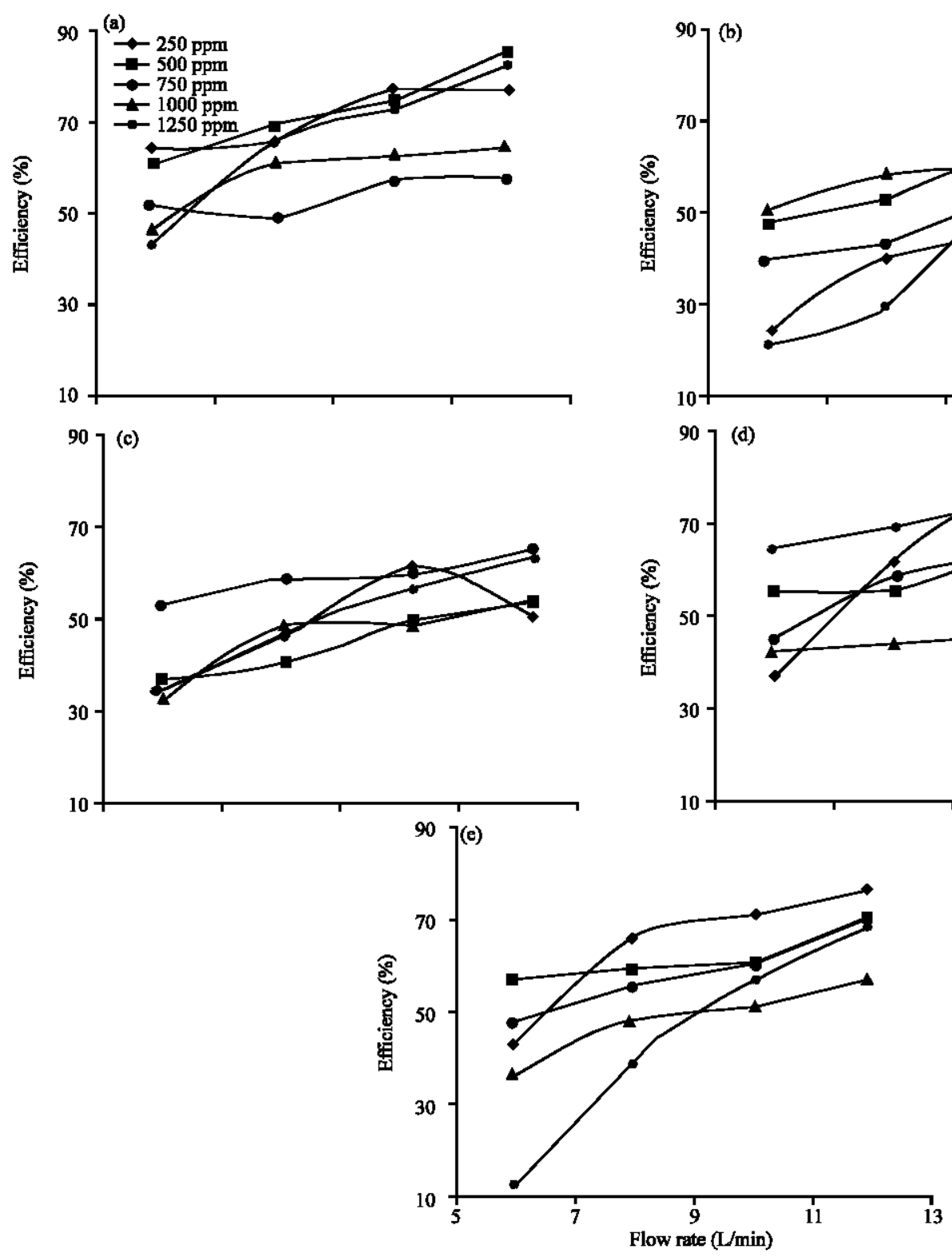
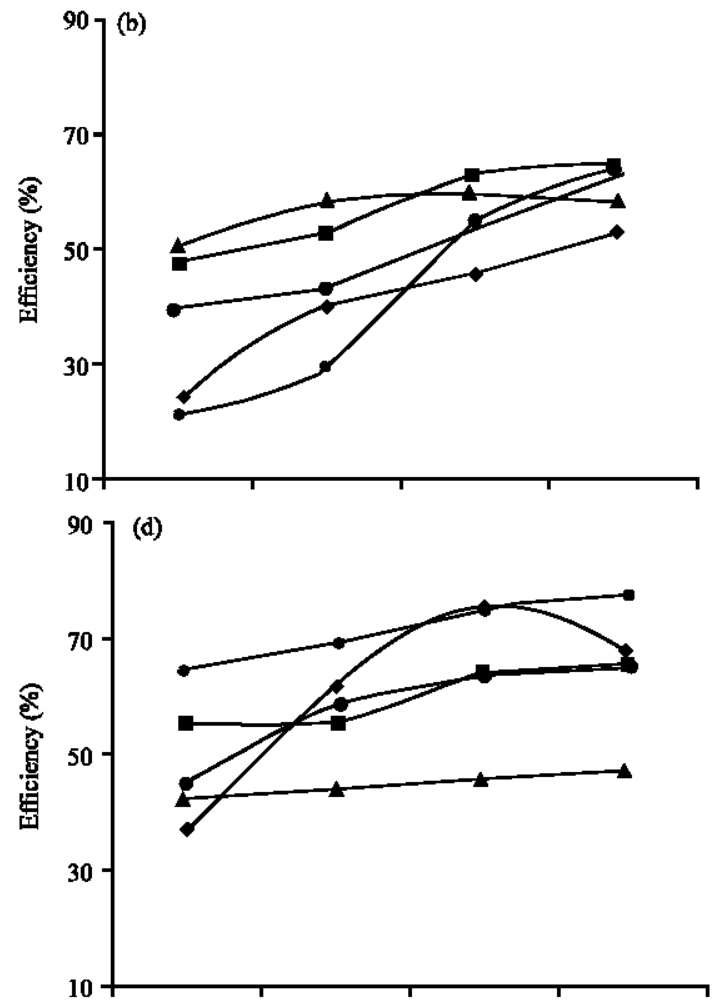

Fig. 4: Effect of operational variables on the separation efficiency of one hydrocyclone; a) $\mathrm{F}=0.1 ; \mathrm{b}) \mathrm{F}=0.3$; $) \mathrm{F}=0.5$; d) $\mathrm{F}=0.7$ and e) $\mathrm{F}=0.9$

$$
E j=\left(1-\frac{C_{u}}{C_{i}}\right) \times 100 \%
$$

It ranges from $0-100$. At complete separation $E j=100$ while $\mathrm{Ej}=0$ when no separation exist in the hydrocyclone.

Effect of feed flow rate on $\mathrm{Ej}$ for one hydrocyclone: Separation efficiency increased with feed flow rate at different inlet oil concentrations and split ratios as shown in Fig. 4. That is because tangential velocity increased monotonically with $\mathrm{Q}_{\mathrm{i}}$ and that leads to make the centrifugal force stronger i.e., greater separation (Tian et al., 2018). Except $500 \mathrm{ppm}$ at split ratios 0.5 and 0.7 has peak values of efficiency with increasing flow rate. This behavior indicates that increasing feed flow rate above a certain value may cause decrease in efficiency as shown in Fig. 4 (C\&D). This is in agreement with (Zhao et al., 2006).

Effect of concentration on $\mathrm{Ej}$ for one hydrocyclone: $\mathrm{C}_{\mathrm{i}}$ has varying influence on hydrocyclone separation as it is interacted with flow rate and split ratio. Higher 


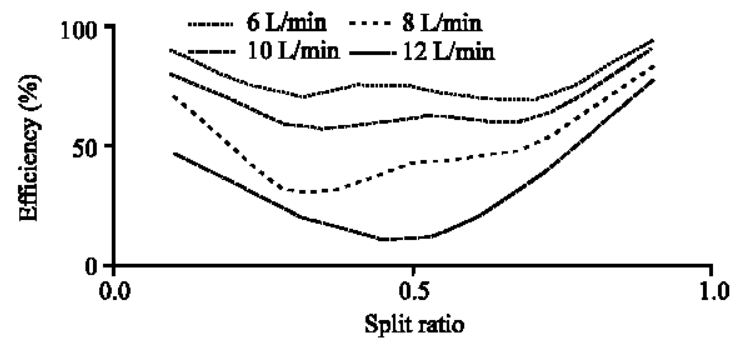

Fig. 5: Effect of changing split ratio at various inlet flow rates for $250 \mathrm{ppm}$ feed inlet oil concentration

concentrations provided higher separation at $0.3,0.5$ and 0.7 split ratios because high concentrations make the coalescence more easily that raising the efficiency (Meyer and Bohnet, 2003) while lower concentrations provided higher separation at 0.1 and 0.9 split ratios because of the influence of pressure as shown in Fig. 4.

Effect of split ratio on Ej for one hydrocyclone: Figure 5 shows the influence of split ratio on $\mathrm{Ej}$ at various flow rates and at $C_{i}=250 \mathrm{ppm}$. With increasing split ratio at the studied range, the $\mathrm{Ej}$ decreased to minimum and then increased to obtain its maximum value. That is because at $\mathrm{F}<0.5 \mathrm{~d}_{u}$ then $\mathrm{Q}_{\mathrm{u}}$ becomes smaller and that leads to decreasing Ej, since, small $\mathrm{Q}_{\mathrm{u}}$ may contain some oil that may raise the concentration fraction of oil and decreases the efficiency. At $\mathrm{F}>0.5 \mathrm{~d}_{\mathrm{o}}$ becomes smaller leading to produce purer water at the underflow that makes the efficiency maximized. Minimum separation efficiency presents at $\mathrm{F}=0.5$ because there is no preference for any of the streams discharged from equally opened valves.

Two hydrocyclones effect on Ej: As reviewed by Bradley (1965) using two or more hydrocyclones in series enhanced the separation of oil-water emulsion. Figure 6 shows that experimentally $\mathrm{Ej}$ for two cyclones is larger than its value for one cyclone. At F $=0.9$ and $\mathrm{C}_{1}=250 \mathrm{ppm}$ Ej was greatly enhanced at lower flow rates while at higher $\mathrm{C}_{\mathrm{i}}$ Ej significantly increased at higher flow rates as shown in Fig. 6a, b. At $\mathrm{F}=0.1$ and $\mathrm{C}_{\mathrm{i}}=250 \mathrm{ppm}$ and higher flow rate the efficiency of one and two cyclones approximately the same. The reason behind this fact is the value of split ratio which is $>0.5$. High values of split ratio means $Q_{u}$ is $>Q_{0}$. At low feed flow rate for $C_{i}=250 \mathrm{ppm}$ forced vortex can not be strong enough to separate lowconcentration oil to overflow stream but when two stage separation (two hydrocyclones) are used the separation is greatly enhanced. At high flow rates, the separation of low-concentration oil is approximately the same for one and two hydrocyclones. That what Fig. 6a clarifies. Figure $6 \mathrm{~b}$ explains the case of high split ratio $\left(\mathrm{Q}_{\mathrm{u}}>\mathrm{Q}_{0}\right)$ and high concentration. At low flowrates forced vortex is weak, so, the separation of one hydrocyclone is low. For two hydrocyclones the separation of high-concentration oil is also of little value because of low flow rate but at high flow rates the separation by two hydrocyclones is greatly enhanced. As a comparison between $\mathrm{A}$ and $\mathrm{B}, \mathrm{Ej}$ has greater values in case A. Figure $6 \mathrm{c}$, d explains the situations of low split ratio $(0.1)$, i.e. $\left(Q_{u}<Q_{0}\right)$. At low concentration ( $250 \mathrm{ppm}$ ), the enhancement of separation is obvious for all flow rates, especially at very high flow rate $(12 \mathrm{~L} / \mathrm{min})$ where the performance of two cyclones is approximately the same as for one cyclone. Figure $6 \mathrm{~d}$ shows the enhancement at all flowrates for high concentration (1250 ppm) and the enhancement is greatly obvious at high flowrates. The reason behind this behavior is when $F$ is smaller than 0.5 , i.e., $Q_{u}<Q_{0}$ a great quantity of oil discharges from overflow opening resulting in purer water from underflow, especially, at high flowrates. From this discussion, it is concluded that using two hydrocyclones is recommended for low oil concentrations, high split ratio and low flowrates. For high concentrations, low split ratio and high flowrates are recommended. So, there is a matter of optimization for the operational variables by using two cyclones as there is an interaction between them.

Pressure Drop Ratio (PDR): PDR is the pressure drop between inlet and outlets of the hydrocyclone and it gives the indication of centrifugal force rejection (Durdevic et al., 2017) its Eq. 2 is as follows:

$$
P D R=\frac{P_{i}-P_{0}}{P_{i}-P_{u}}
$$

PDR for one hydrocyclone: PDR for one hydrocyclone deviates from 1 when flow rate is increased and when split ratio drifts away from 0.5 as shown in Fig. 7. That's because at small flow rates and at split ratio around 0.5 , pressures in the outlets is zero that makes PDR equal or close to 1 while at larger flow rates and at split ratios far away from $0.5, \mathrm{p}_{\mathrm{o}}$ and $\mathrm{p}_{\mathrm{u}}$ have significant values that make PDR deviates from 1 . The PDR varied monotonically with flow rate at split ratios $<0.5$ while it is changed reversely with flow rate at split ratios more than 0.5 .

PDR for two hydrocyclones: Figure 8 shows a comparison between one and two hydrocyclones of PDR with the influence of flow rates at $F=0.9$. As it is obvious from the figure PDR for two cyclones is less than for one cyclone that's because the feed flow rate breaks into over and under flow streams and then the over flow enters the second cyclone and breaks into over and under flow streams which make the pressures of the latter streams zero or close to zero and produce $\mathrm{PDR}=1$ or very close to it. 

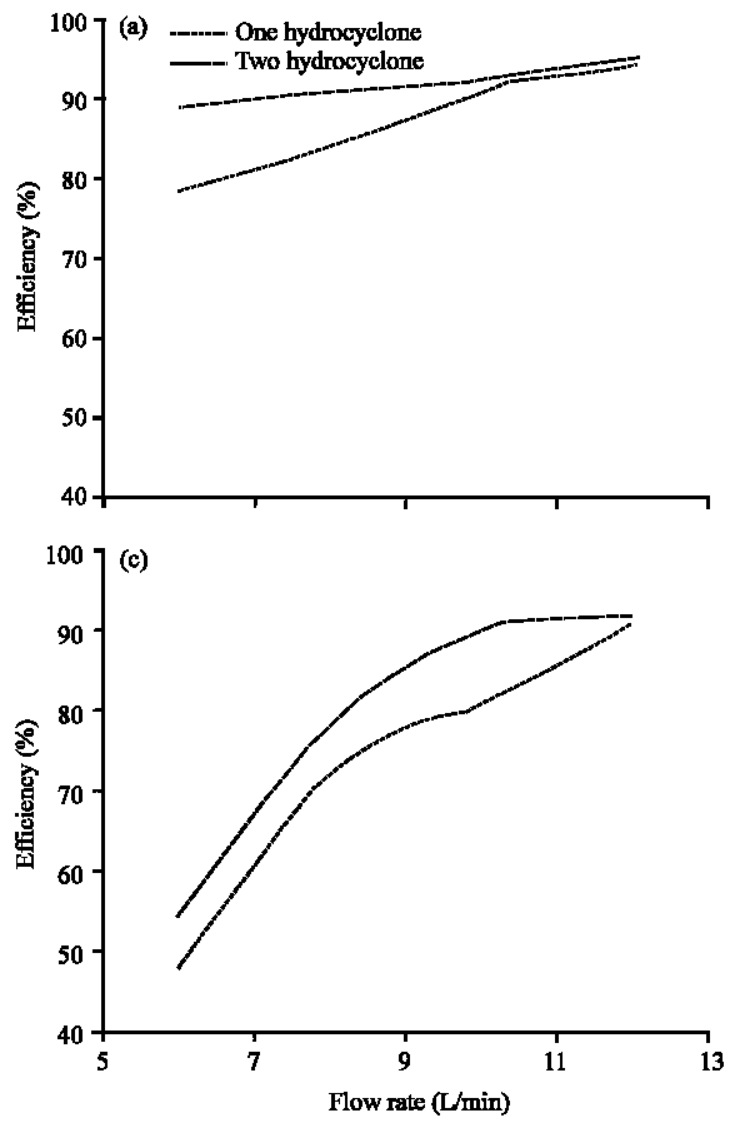
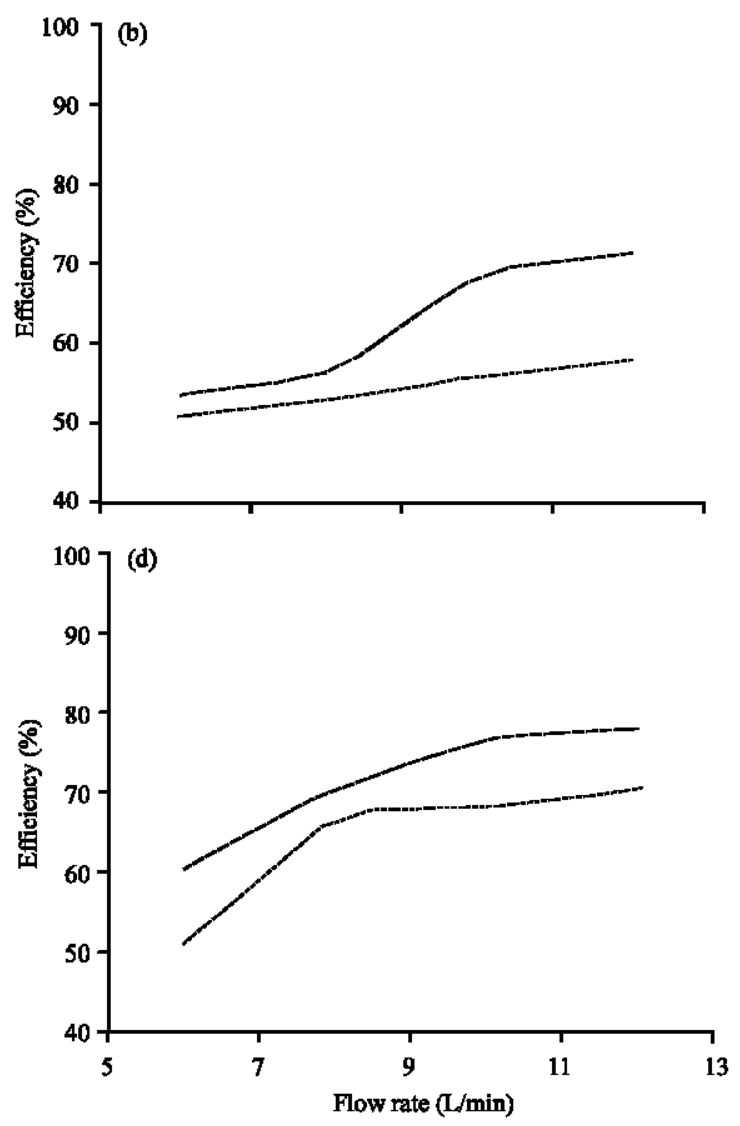

Fig. 6: Effect doubling hydrocyclone on the separation efficiency at various feed flow rate; a) at $\mathrm{F}=0.9, \mathrm{C}_{\mathrm{i}}=250 \mathrm{ppm}$; b) at $F=0.9, C_{i}=1250 \mathrm{ppm} ; \mathrm{c}$ ) at $\mathrm{F}=0.1, \mathrm{C}_{\mathrm{i}}=250 \mathrm{ppm}$ and d) at $\mathrm{F}=0.1, \mathrm{C}_{\mathrm{i}}=1250 \mathrm{ppm}$

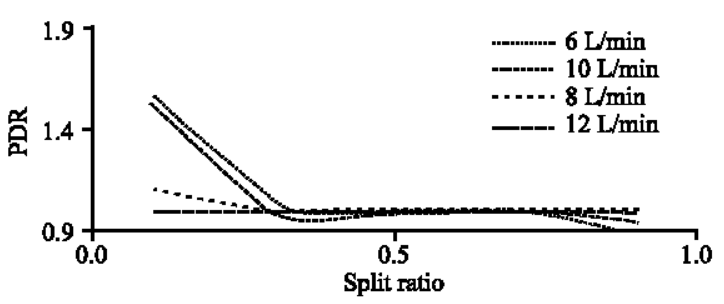

Fig. 7: Effect of changing split ratio on PDR for various flow rates

Optimization of the operational variables: According to the above discussions of the operational variables on $\mathrm{Ej}$ and PDR, the optimization must be sought to obtain the optimum conditions that give the maximum separation efficiency and minimum PDR. Optimization of the operational variables using $2^{3}$ factorial experimental design performed with Minitab program gave the optimum conditions at $12 \mathrm{~L} / \mathrm{min}$ feed flow rate, $250 \mathrm{ppm}$ feed oil concentration and 0.9 split ratio which corresponds to maximum separation efficiency (94.78) and minimum PDR

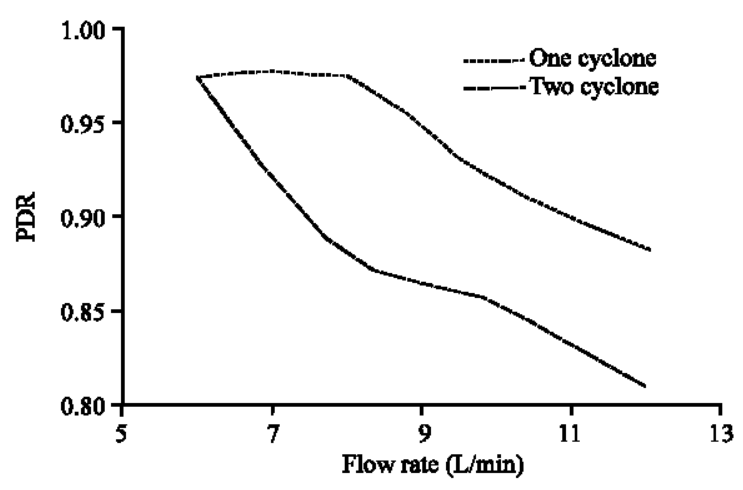

Fig. 8: Effect of flow rate on PDR at 0.9 split ratio

(0.895) for one hydrocyclone. The optimum conditions for two hydrocyclones are $\mathrm{Ej}=95.2 \%$ and $\mathrm{PDR}=0.86$ at the same optimum conditions for one hydrocyclone. Minitab predicted the equations that express $\mathrm{PDR}$ and $\mathrm{Ej}$ as a function of $F, Q_{i}$ and $C_{i}$ for one and two hydrocyclones as follows: 


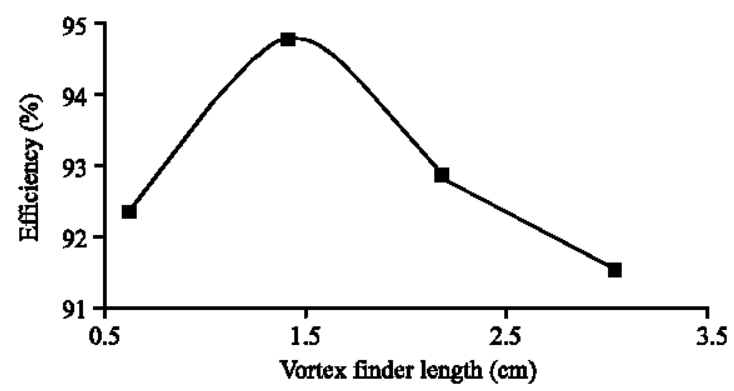

Fig. 9: Effect of VFL on separation efficiency

$$
\begin{aligned}
& E j=14.14-164.8 \mathrm{~F}+0.01626 \mathrm{C}_{\mathrm{i}}+7.135 \mathrm{Q}_{\mathrm{i}}+ \\
& \left(0.1030 \mathrm{~F}^{*} \mathrm{C}_{\mathrm{i}}\right)+\left(10.38 \mathrm{~F}^{*} \mathrm{Q}_{\mathrm{i}}\right)-\left(0.003139 \mathrm{C}_{\mathrm{i}}{ }^{*} \mathrm{Q}_{\mathrm{i}}\right)- \\
& \left(0.007246 \mathrm{~F}^{*} \mathrm{C}_{\mathrm{i}}{ }^{*} \mathrm{Q}_{\mathrm{i}}\right) \\
& \mathrm{Ej}=-220.9+320.4 \mathrm{~F}+0.1086 \mathrm{C}_{\mathrm{i}}+21.07 \mathrm{Q}_{\mathrm{i}}- \\
& \left(0.1416 \mathrm{~F}^{*} \mathrm{C}_{\mathrm{i}}\right)-\left(19.99 \mathrm{~F} \mathrm{Q}_{\mathrm{i}}\right)-\left(0.001939 \mathrm{C}_{\mathrm{i}}{ }^{*} \mathrm{Q}_{\mathrm{i}}\right)^{+} \\
& \left(0.000354 \mathrm{~F}^{*} \mathrm{C}_{\mathrm{i}}{ }^{*} \mathrm{Q}_{\mathrm{i}}\right) \\
& \mathrm{PDR}=0.3569+0.8312 \mathrm{~F}+0.1072 \mathrm{Q}_{\mathrm{i}}-\left(0.1385 \mathrm{~F}^{*} \mathrm{Q}_{\mathrm{i}}\right) \\
& \mathrm{Ej}=-0.1106+105.0 \mathrm{~F}+0.03448 \mathrm{C}_{\mathrm{i}}+7.921 \mathrm{Q}_{\mathrm{i}}- \\
& \left(0.08982 \mathrm{~F}^{*} \mathrm{C}_{\mathrm{i}}\right)-\left(8.101 \mathrm{~F} * \mathrm{Q}_{\mathrm{i}}\right)-\left(0.003906 \mathrm{C}_{\mathrm{i}}{ }^{*} \mathrm{Q}_{\mathrm{i}}\right)+ \\
& \left(0.006144 \mathrm{~F}^{*} \mathrm{C}_{\mathrm{i}}{ }^{*} \mathrm{Q}_{\mathrm{i}}\right)
\end{aligned}
$$$$
\mathrm{PDR}=1.073+0.07500 \mathrm{~F}-0.01208 \mathrm{Q}_{\mathrm{i}}-\left(0.01250 \mathrm{~F} * \mathrm{Q}_{\mathrm{i}}\right)
$$

Equation 3-5 express $\mathrm{Ej}$ at $\mathrm{F}<0.5, \mathrm{Ej}$ at $\mathrm{F}>0.5$ and $\mathrm{PDR}$, respectively by using one hydrocyclone while Eq. 6 and 7 express Ej and PDR, respectively, for two hydrocyclones in series. When applying the operational variables in Eq. 3 and 4 it is obvious that it affects $\mathrm{Ej}$ in the order, flow rate $>$ split ratio $>$ concentration for one hydrocyclone.

Vortex finder: The optimized conditions of $\left(\mathrm{Q}_{\mathrm{i}}, \mathrm{C}_{\mathrm{i}}, \mathrm{F}\right)$ for one hydrocyclone set to study the effect of changing Vortex Finder Length (VFL) on Ej and PDR. Effect of VFL on $\mathrm{Ej}$ for one hydrocyclone, Fig. 9 shows the effect of changing VFL on separation efficiency. In the studied range of VFL, separation efficiency shows maximum value at the design value $(1.3 \mathrm{~cm})$. That is because lengthy vortex finder prevents the water from flowing to the overflow stream and directs it to the underflow stream and induce the oil to the overflow stream. This is in agreement with the literature (Martinez et al., 2008). So, short vortex finder reduces the separation efficiency. This is the case of VFL $<1.3 \mathrm{~cm}$ which is in agreement with that of Zhao et al. (2006). So, changing VFL from the designed value $(1.3 \mathrm{~cm})$ makes the efficiency worse and let it decrease from 94.78 to $91.5 \%$ in the studied range.

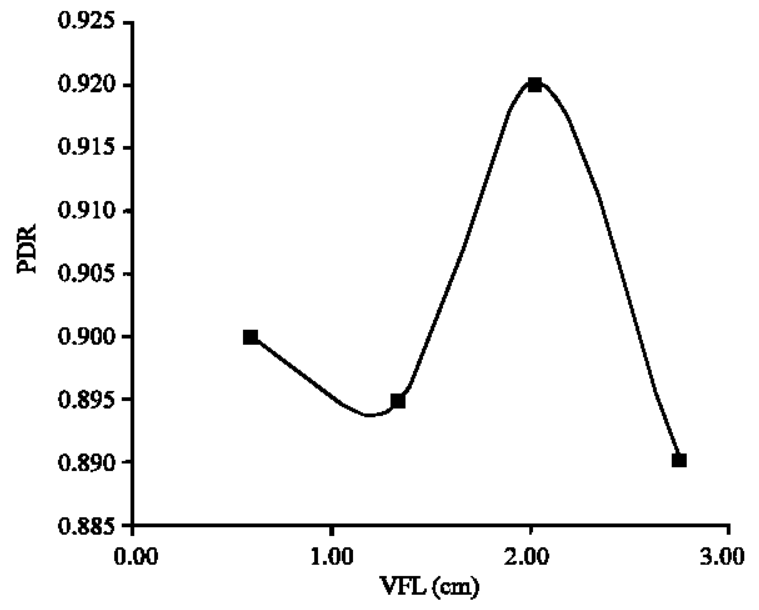

Fig. 10: Effect of VFL on PDR

Effect of VFL on PDR: Figure 10 represents the effect of varying vortex finder length on pressure drop ratio. At the studied range of VFL the pressure drop ratio does not greatly changed. As the pressures of inlet and outlets does not significantly influenced with VFL with the exception that the curve fluctuates and gives maximum value at $\mathrm{VFL}=2 \mathrm{~cm}$. The minimum value of $\mathrm{PDR}$ is 0.89 which corresponds VFL $=2.7 \mathrm{~cm}$ because the longer VFL the greater amount of water discharges from the underflow making the forced vortex weaker and the PDR lower. The designed value of VFL $(1.3 \mathrm{~cm})$ shows somewhat increasing of PDR over the minimum value at 0.894 but it has a maximum percentage efficiency.

\section{CONCLUSION}

The conclusions obtained from the research are listed split ratio, inlet concentration and feed flow rate influenced the separation efficiency. $F$ and $Q_{i}$ only affected PDR while $\mathrm{C}_{\mathrm{i}}$ have no effect on it for one and two hydrocyclones. Using two identical hydrocyclones in series enhanced the separation significantly when one hydrocyclone efficiency is low and vice versa at higher efficiency of one hydrocyclone the enhancement is not significant while PDR is significantly decreased.

Optimization of the experiments shows that at $\mathrm{Q}_{\mathrm{i}}=12 \mathrm{~L} / \mathrm{min}, \mathrm{C}_{\mathrm{i}}=250 \mathrm{ppm}$ and $\mathrm{F}=0.9$ gave maximum separation efficiency (94.78\%) and minimum PDR (0.895) for one hydrocyclone while $\mathrm{Ej}=95.2 \%$ and $\mathrm{PDR}=0.86$ for two hydrocyclones. Changing VFL from the designed value decreased the efficiency. Applying Minitab program is successful in assigning the optimum operating conditions and expressing the influential effect in equations that can be generalized. 


\section{NOMENCLATURE}

\section{Roman symbols:}

$\begin{array}{lll}\text { Symbol } & & \text { Description/Units } \\ \mathrm{C} & = & \text { Oil Concentration }(\mathrm{ppm}) \\ \mathrm{d}_{50} & = & \text { Droplet size }(\mu \mathrm{m}) \\ \mathrm{d} & = & \text { Diameter }(\mathrm{cm}) \\ \mathrm{E}_{\mathrm{j}} & = & \text { Separation efficiency ----- } \\ \mathrm{F} & = & \text { Split ratio ----- } \\ \mathrm{h} & = & \text { Hydrocyclone thickness }(\mathrm{cm}) \\ \mathrm{L}_{1} & = & \text { Cylinder length }(\mathrm{cm}) \\ \mathrm{P} & = & \text { Pressure }(\text { bar }) \\ \mathrm{Q} & = & \text { Flow rate }(\mathrm{L} / \mathrm{min})\end{array}$

Greek symbols:

$\begin{array}{lll}\eta & = & \text { Viscosity of the oil }(\mathrm{cp}) \\ \theta & = & \text { Angle of conical section ----- } \\ \rho & = & \text { Density of water }\left(\mathrm{g} / \mathrm{cm}^{3}\right) \\ \sigma & = & \text { Density of oil }\left(\mathrm{g} / \mathrm{cm}^{3}\right)\end{array}$

\section{Subscript:}

$\begin{array}{lll}\text { Symbol } & & \text { Description } \\ \mathrm{c} & = & \text { Cyclone } \\ \mathrm{i} & = & \text { Inlet } \\ \mathrm{o} & = & \text { Overflow } \\ \mathrm{u} & = & \text { Underflow }\end{array}$

$\begin{array}{lll}\text { Abbreviations: } & \\ \text { Name } & = & \text { Description/Units } \\ \text { CFD } & = & \text { Computational Fluid Dynamics ----- } \\ \text { PDR } & = & \text { Pressure Drop Ratio ----- } \\ \text { VFL } & = & \text { Vortex Finder Length }(\mathrm{cm})\end{array}$

\section{REFERENCES}

Barbosa, E.A., L.G.M. Vieira, C.A.K. Almeida, J.J.R. Damasceno and M.A.S. Barrozo, 2003. Differences of behavior between filtering hydrocyclone with Bradley and Rietema geometry. Mater. Sci. Forum, 416: 317-322.

Bradley, D., 1965. The Hydrocyclone. 1st Edn., Pergamon Press, Oxford, UK., ISBN:9781 483155708, Pages: 348.

Cilliers, J.J., 2000. Hydrocyclones for Particle Size Separation. In: II Particle Size Separation, Cilliers, J.J. (Ed.). University of Manchester Institute of Science and Technology, Manchester, UK., pp: 1819-1825.

Durdevic, P., S. Pedersen and Z. Yang, 2017. Challenges in modelling and control of offshore de-oiling hydrocyclone systems. J. Phys. Conf. Ser., 783: 1-10.

Fan, X., 2016. Oil-water separation efficiency and fluid mechanics of a hydrocyclone. Proceedings of the 2016 7th International Conference on Mechatronics, Control and Materials (ICMCM 2016), December 29, 2016, Atlantis Press, Wolvercote, England, ISBN: 978-94-6252-267-1, pp: 185-191.
Gomez, C., J. Caldentey, S. Wang, L. Gomez and R. Mohan et al., 2002. Oil/water separation in Liquid/Liquid Hydrocyclones (LLHC): Part 1-Experimental investigation. SPE J., 7: 353-372.

Hosseini, S.M., K. Shahbazi and M.R.K. Nikou, 2015. A CFD simulation of the parameters affecting the performance of downhole de-oiling hydrocyclone. Iran. J. Oil Gas Sci. Technol., 4: 77-93.

Kharoua, N., L. Khezzar and Z. Nemouchi, 2010a. Computational fluid dynamics study of the parameters affecting oil-water hydrocyclone performance. Proc. Inst. Mech. Eng. Part E. J. Process Mech. Eng., 224: 119-128.

Kharoua, N., L. Khezzar and Z. Nemouchi, $2010 \mathrm{~b}$. Hydrocyclones for de-oiling applications-A review. Pet. Sci. Technol., 28: 738-755.

Martinez, L.F., A.G. Lavin, M.M. Mahamud and J.L. Bueno, 2008. Vortex finder optimum length in hydrocyclone separation. Chem. Eng. Process. Process Intensif., 47: 192-199.

Meyer, M. and M. Bohnet, 2003. Influence of entrance droplet size distribution and feed concentration on separation of immiscible liquids using hydrocyclones. Chem. Eng. Technol., 26: 660-665.

Motin, A. and A. Benard, 2017. Design of liquid-liquid separation hydrocyclones using parabolic and hyperbolic swirl chambers for efficiency enhancement. Chem. Eng. Res. Des., 122: 184-197.

Saidi, M., R. Maddahian and B. Farhanieh, 2012. A parametric study on deoiling hydrocyclones flow field. World Acad. Sci. Eng. Technol. Intl. J. Mech. Aerosp. Ind. Mechatronic Manuf. Eng., 6: 1824-1828.

Tian, J., L. Ni, T. Song, J. Olson and J. Zhao, 2018. An overview of operating parameters and conditions in hydrocyclones for enhanced separations. Sep. Purif. Technol., 206: 268-285.

Yan, X., Y. Lin, W. Zunce, L. Sen and Z. Jinglong et al., 2015. Experimental study on downhole oil-water separation hydrocyclone. Open Pet. Eng. J., 8: 257-261.

Young, G.A.B., W.D. Wakley, D.L. Taggart, S.L. Andrews and J.R. Worrell, 1994. Oil-water separation using hydrocyclones: An experimental search for optimum dimensions. J. pet. Sci. Eng., 11:37-50.

Zhao, L., M. Jiang, F. Li, H. Song and S. Liu, 2006. Effects of geometric and operating parameters on the separation performance of air-injected de-oil hydrocyclone. Proceedings of the OMAE2006 25th International Conference on Offshore Mechanics and Arctic Engineering, June 4-9, 2006, Hamburg, Germany, pp: 1-7. 